\title{
Diversity of behavioural patterns displayed by a summer feeding aggregation of Atlantic sturgeon in the intertidal region of Minas Basin, Bay of Fundy, Canada
}

\author{
Montana F. McLean ${ }^{1, *}$, Colin A. Simpfendorfer ${ }^{2}$, Michelle R. Heupel ${ }^{2,3}$, \\ Michael J. Dadswell ${ }^{1}$, Michael J. W. Stokesbury ${ }^{1}$ \\ ${ }^{1}$ Biology Department, Acadia University, 33 Westwood Ave. Wolfville, Nova Scotia B4P 2R6, Canada \\ ${ }^{2}$ Centre for Sustainable Tropical Fisheries and Aquaculture, School of Earth and Environmental Sciences, \\ James Cook University, Townsville, Queensland 4811, Australia \\ ${ }^{3}$ Australian Institute of Marine Science, Townsville, Queensland 4810, Australia
}

\begin{abstract}
Quantifying animal movements can reveal spatial and temporal patterns of habitat use and may improve our understanding of the foraging strategies of marine predators where direct observations of feeding behaviour are rare or impossible because of turbidity. Fine-scale movement data from 25 acoustically tagged Atlantic sturgeon Acipenser oxyrinchus (Mitchill, 1815) were gathered using a Vemco Positioning System array of hydroacoustic receivers in the intertidal zone of Minas Basin, Bay of Fundy, Canada, during summer 2011. From these data, sturgeon relocations and movement trajectories were determined. Sturgeon movement trajectories were categorized into 3 movement types by analyzing 4 calculated metric variables including (1) mean distance between successive relocations; (2) mean relative angle or 'turning angle'; (3) mean rate of movement $\left(\mathrm{ROM}_{;} \mathrm{m} \mathrm{s}^{-1}\right)$; and (4) a linearity ratio. Movement Type 1 trajectories were characteristically slow and winding, with short steps between relocation, whereas Type 2 movements were fast and tortuous. Movement Type 3 trajectories were fast and linear, with large steps between relocations. Considerable variability in movement type was recognized with 11 individuals performing all 3 types of movement during the monitoring period. Movement Types 1 and 2 occurred primarily over the intertidal zone, where sediment type was comprised of larger sand and sandy/silt particles. This association with larger grain size may coincide with a diet preference for sand-tube dwelling polychaetes and indicates the importance of the intertidal zone to foraging Atlantic sturgeon. All movement types were equally likely to occur throughout a $24 \mathrm{~h}$ day and throughout all tidal stages; however, there was higher overall crepuscular activity which revealed a temporal pattern not previously recognized for Atlantic sturgeon.
\end{abstract}

KEY WORDS: Atlantic sturgeon - Acoustic telemetry - Vemco Positioning System - VPS · Fine-scale movement · Trajectory $\cdot$ Intertidal $\cdot$ Crepuscular activity $\cdot$ Spatial and temporal patterns

\section{INTRODUCTION}

Recent advances in acoustic telemetry technology now allow simultaneous monitoring of multiple individuals from a population (Heupel et al. 2004) and permit researchers to answer questions relevant to fisheries management. Acoustic telemetry can also be used to test hypotheses important to the development of conservation strategies for near-threatened (Moser \& Lindley 2007, Lindley et al. 2008), threatened (Fox et al. 2000) or endangered species (Hissmann et al. 2000, Welch et al. 2009, Simpfendorfer et 
al. 2010), including information about their life histories (Lindley et al. 2008). By studying an animal's movement, behavioural and ecological processes fundamental to its overall survival and fitness (such as navigation, migration, dispersal, space use and food searching) can be determined.

Species-specific characteristics of movement are central to determining how animals use areas, and therefore what areas may be most important to protect. Habitat use and spatial distribution have commonly been described through the use of kernel utilization densities and convex polygons to estimate activity space (Heupel et al. 2004, Collins et al. 2007, Yeiser et al. 2008), and/or residency times (Holland et al. 1993, Collins et al. 2007); however, these data are not often used to examine the underlying behavioural patterns demonstrated by such movements. Fine-scale spatial and temporal movement data provided by electronic tags have been used to classify animal movement into various behavioural categories, such as foraging versus migratory or transitory (Austin et al. 2004, Jonsen et al. 2007, Bailey et al. 2008, Heupel et al. 2012). The trajectory of an animal track, or curve recorded by a tagged animal when it moves, can be analyzed to segregate these recorded behaviours (Calenge 2011). The tortuosity versus linearity of a curve can further be assessed in order to categorize behaviour (Benhamou 2004, Heupel et al. 2012). During foraging, animal movements tend to be more tortuous in nature, with smaller turn angles and less time between subsequent relocations or steps (Benhamou 2004). Recently, behavioural patterns of some species have been examined using the Vemco Positioning System (VPS) which provides fine-scale data on animals carrying acoustic telemetry tags moving through a dense array of hydroacoustic receivers (Espinoza et al. 2011a,b, Farrugia et al. 2011, Reubens et al. 2011).

Atlantic sturgeon Acipenser oxyrinchus (Mitchill, 1815) are a long-lived, slow growing species that historically supported a commercial fishery in the USA (Vladykov \& Greeley 1963, ASMFC 1998). Overharvesting at the turn of the 19th century, coupled with habitat degradation, pollution and loss of suitable spawning habitat caused extirpation in some rivers (Dadswell 2006), and in response the USA declared a fishing moratorium on Atlantic sturgeon in 1997 (ASMFC 1998). More recently, 4 of the 5 distinct population segments of Atlantic sturgeon along the eastern USA were listed as 'endangered' and one as 'threatened' under the Endangered Species Act (NOAA 2012a,b). In Canada, there are 2 known spawning populations located in the Saint John River
(New Brunswick) and St. Lawrence River (Quebec). In 2011, the Saint John River population was listed by the Committee on the Status of Endangered Wildlife in Canada as threatened, under the Species At Risk Act (COSEWIC 2011). Both the Saint John River and St. Lawrence River populations, however, continue to support commercial fisheries (DFO 2012).

Coastal migrations are common for sub-adult and adult Atlantic sturgeon, and a certain degree of mixing between the stocks has occurred at foraging sites (Wirgin et al. 2012). During the summer months, the Minas Basin in the Bay of Fundy is a terminus for approximately 10000 migrating Atlantic sturgeon (S. Wehrell \& M. Dadswell unpubl. data). Acoustic telemetry has been used to attempt to determine stock structure and migration patterns for Atlantic sturgeon over much of their range from the Gulf of St. Lawrence, Quebec in the north, to parts of Georgia in the USA in the south (Moser \& Ross 1995, Collins et al. 2000, Hatin et al. 2007, Fernandes et al. 2010, Fox \& Breece 2010, Erickson et al. 2011). Seasonal movements of Atlantic sturgeon have been described to and from their spawning rivers (Collins et al. 2000, Hatin et al. 2007), overwintering sites (Erickson et al. 2011) and feeding grounds (Kieffer \& Kynard 1993). Although research is extensive, none of these studies have quantified the behavioural traits underlying the observed movements.

Suitable sturgeon foraging areas in the Minas Basin are patchy, with mudflats interspersed with sand bars and gravel. Much of the preferred diet of Atlantic sturgeon is located in the mid-upper reaches of the intertidal zone over sandy bottom (McLean et al. 2013). We hypothesized that, because foraging areas in Minas Basin are patchy and only available at certain stages of the tide, sturgeon will display a number of behaviours - including transitory, searching and foraging - as they move from one food patch to another. The time Atlantic sturgeon allocate to searching and foraging is important to their conservation, as the semi-diurnal tides remove much of the available feeding grounds during lower water levels. This means that the time spent foraging during high tide is critical, as the sturgeon must obtain their daily ration when resources are available. Considerable ground fish trawling occurs over important sturgeon foraging areas in the Minas Basin during the summer months at high tide (Beardsall et al. 2013), posing a potential threat if sturgeon were to be displaced from foraging areas or captured as by-catch.

Our study had 2 overall objectives. The first was to develop a procedure to quantify Atlantic sturgeon movement in the intertidal regions so that move- 


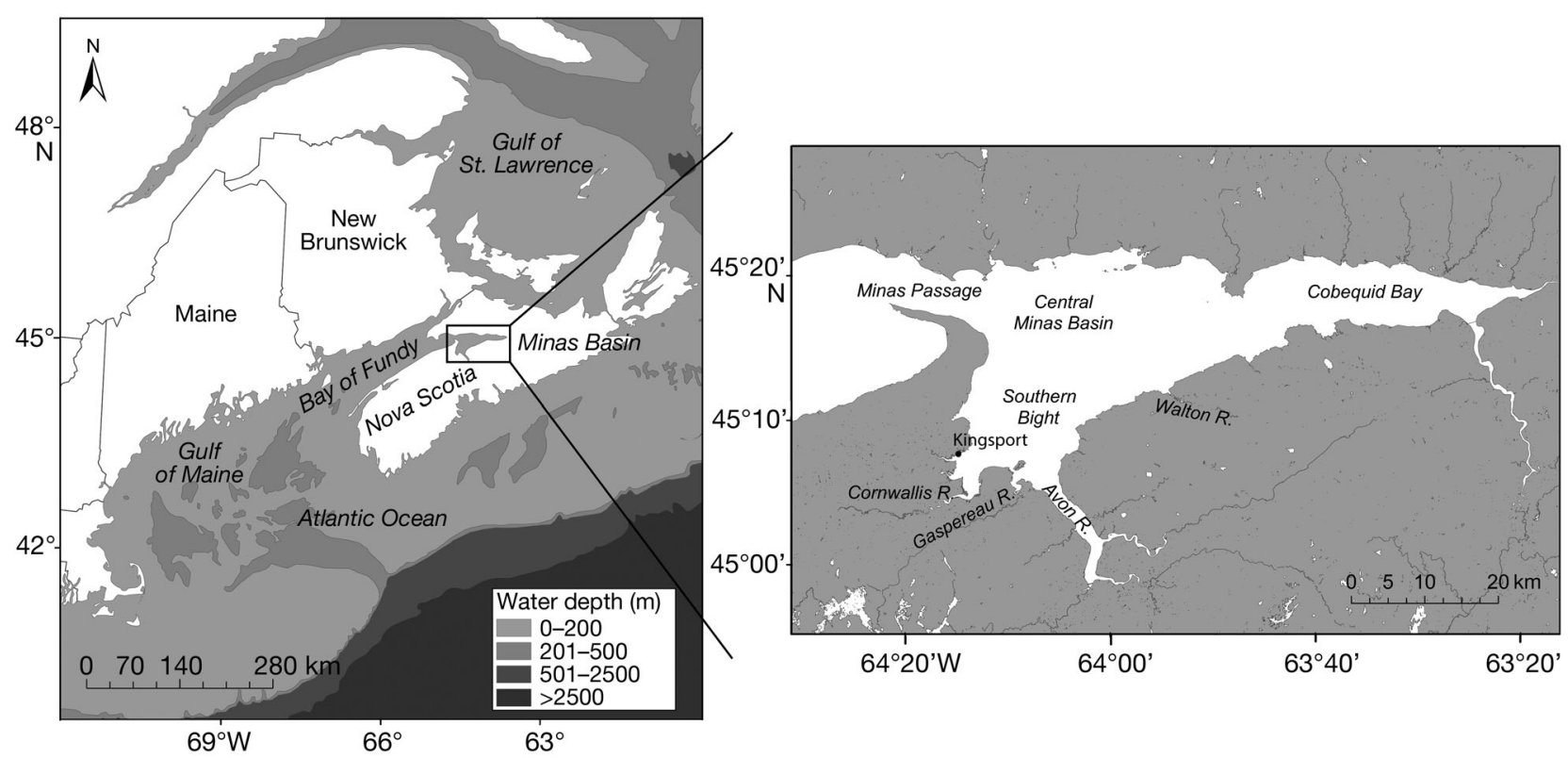

Fig. 1. The Minas Basin is the northeastern portion of the Bay of Fundy. It is separated into 4 distinct regions: Minas Passage (which connects Minas Basin to the rest of the Bay of Fundy), Central Minas Basin, Cobequid Bay, and Southern Bight

ments indicative of feeding and transitory behaviour could be identified. The second was to define the relationship between movement behaviours and the tidal and diurnal cycles. Tidal and diurnal cycles may be time-varying drivers of behaviour whose influence needs to be understood to put movement behaviours in context both spatially and temporally. Taken together, these objectives have allowed us to gain a better understanding of the biotic and physical drivers of sturgeon behaviour.

\section{MATERIALS AND METHODS}

\section{Study site}

Sturgeon movements were examined in the tidal region of Kingsport Beach, Minas Basin (Fig. 1). Minas Basin is a shallow estuarine water body connected to the Bay of Fundy by a narrow channel, through which large amounts of water transit the system on the semi-diurnal tides (Fig. 1). Average tidal amplitude is $11.5 \mathrm{~m}$, with record highs surpassing $16 \mathrm{~m}$ on some spring tides (Bousfield \& Leim 1958). Much of the Minas Basin has a depth less than $25 \mathrm{~m}$ at low tide, with the exception of the Minas Passage which reaches depths up to $115 \mathrm{~m}$ (Bousfield \& Leim 1958, Percy 2001). Minas Basin and Minas Passage experience extensive tidal mixing (Bousfield \& Leim 1958). The physical characteristics and extreme tides along with shallow bathymetric gradients create a 1 to $2 \mathrm{~km}$ wide intertidal zone with varying sediment composition (Yeo \& Risk 1979). The mean $( \pm \mathrm{SD})$ clay to sand ratio at Kingsport Beach (Fig. 1) is $0.3 \pm 0.2$ (McLean 2013), which means much of the area is composed of sandy/silt sediments with small patches of sand, silt, and clay dispersed throughout.

\section{Field methods}

A total of 83 Atlantic sturgeon were captured by weir and otter-trawl during June to August of 2010 and 2011. Weir catches were made on the north shore of Central Minas Basin whereas trawls were performed within the Southern Bight within close proximity to Kingsport Beach (Fig. 1). Transmitters (V16 series, $16 \mathrm{~mm} \times 65 \mathrm{~mm}$, Nova Scotia) were surgically implanted into the abdominal cavity. To facilitate transmitter insertion, a large PVC cradle capped on one end was tipped at a $45^{\circ}$ angle to allow water to pool. A stock solution of $10 \mathrm{mg} \mathrm{l}^{-1}$ of MS-222 (3-aminobenzoic acid-ethyl-ester-methane sulphate) was mixed with $20 \mathrm{l}$ of fresh seawater and poured into the PVC cradle. Fish were placed dorsal side up with their head and gills fully submerged in the anaesthesia bath until opercular movements slowed and the fish were unresponsive to a tail grab. They were then removed from the bath and placed ventral side up on a moistened tarpaulin. All equipment (including transmitters) was disinfected prior to surgery using a $10 \%$ Betadine solution, followed by a 

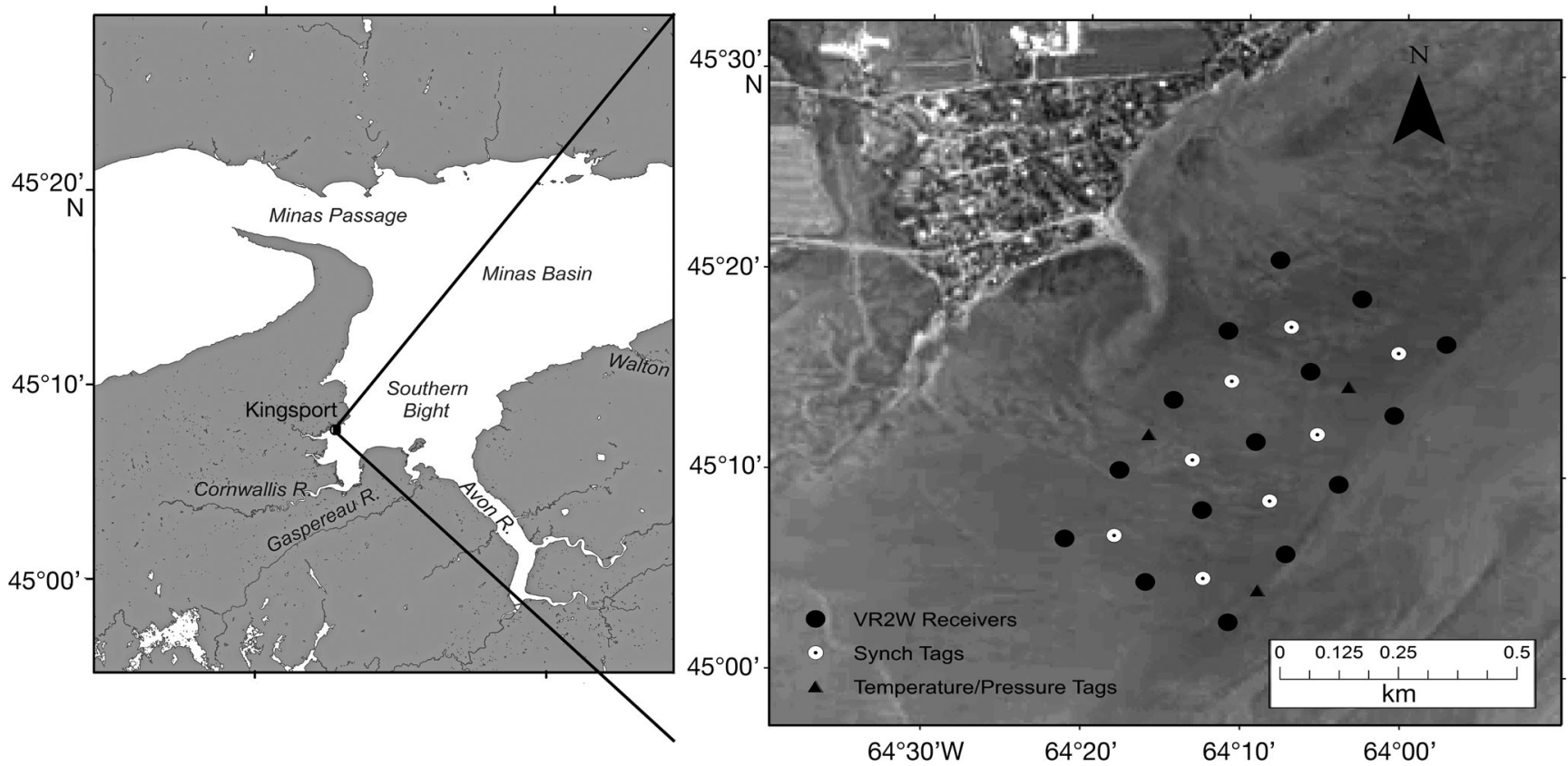

Fig. 2. Vemco Positioning System (VPS) array deployed at Kingsport beach, in the Southern Bight of Minas Basin to examine fine-scale movement behaviour of acoustically tagged Atlantic sturgeon Acipenser oxyrinchus. The array consisted of 15 VR2W receivers, 8 synchronization tags, and 3 temperature and pressure sensor tags

saline rinse. A 3 to $4 \mathrm{~cm}$ incision was made on the ventral surface on either side of the linea alba; generally posterior to the pelvic girdle. Transmitters were inserted and pushed approximately $4 \mathrm{~cm}$ anteriorly using the tip of a blunt probe. Two horizontal mattress sutures, using sterile absorbable 1/0 Ethilon monofilament nylon sutures with a reverse cutting edge (Johnson \& Johnson), were used to close the incision site. Surgeries lasted 2 to 4 min, excluding anaesthesia and recovery time. Post-surgery, sturgeon were held in a recovery tank and allowed sufficient time for the anaesthesia to wear off and for their condition to be monitored before being released in an area near the capture site. Prior to release, all sturgeon were also marked with an external dart tag (FLOY) and an internal Passive Integrated Transponder tag, measured to the nearest fork length in $\mathrm{cm}$, weighed to the nearest $\mathrm{g}$, and sampled for DNA analyses.

The presence and movements of acoustically tagged sturgeon were monitored using a gridded array of 15 VR2W omnidirectional acoustic receivers (Vemco) with overlapping detection ranges deployed on Kingsport Beach (Fig. 2). Units were moored on steel rebar posts at low tide so they could be secured into sediment. Units were deployed so the hydrophone was $45 \mathrm{~cm}$ above the sediment. Three temperature and pressure tags (V16TP-6X, $69 \mathrm{kHz}$ ), with nominal code transmission delays of $900 \mathrm{~s}$ (600 to
1200 s), were stationed throughout the acoustic array to measure thermal gradients and water level (Fig. 2).

A range test was conducted prior to deployment of receivers to determine the acoustic range and detection efficiency of each receiver (Simpfendorfer et al. 2008, Espinoza et al. 2011a,b). Two VR2W receivers were placed $600 \mathrm{~m}$ apart with 3 single coded transmitters (Vemco V16-6X, 69kHz) placed at fixed locations between them for approximately $45 \mathrm{~h}$. Placement of equipment ensured testing between 100 and $500 \mathrm{~m}$. Detection efficiency was high $(\sim 90 \%)$ at all distances up to $500 \mathrm{~m}$. Receivers were, however, placed at $200 \mathrm{~m}$ intervals to increase the area of overlapping detections by 3 or more receivers.

Eight synchronizing transmitters or 'sync tags' (Vemco V16-6X, $69 \mathrm{kHz}$ ), with a nominal code transmission delay of $60 \mathrm{~s}$ (range 30 to $90 \mathrm{~s}$ ), were also deployed within the array to correct for internal clock drift and synchronize the internal clocks of receivers at the post-retrieval stage (Fig. 2). Sync tags were placed $<100 \mathrm{~m}$ from each receiver to ensure the best possible time synchronization (Espinoza et al. $2011 \mathrm{a}, \mathrm{b})$. The VPS of acoustic tags and sync tags allowed triangulation of an individual through the use of differences in detection arrival times at 3 or more receivers.

VPS software (Vemco) was used to analyze VPS and horizontal position error (HPE) data. The HPE is 
the radius of the estimated circular error associated with each calculated position (Espinoza et al. 2011a, see also Smith 2013). Data were classified according to tidal state (flood, ebb, low water, high water, and mid-water/slack) and diel stage (day, night). Accurate tide tables supplied by the Government of Canada (www.waterlevels.gc.ca) were used for high and low tide times. Sunrise and sunset data were obtained from the National Research Council Canada for the Halifax region (www.nrc-cnrc.gc.ca/ eng/services/hia/sunrise-sunset.html).

\section{Trajectory analysis}

To assess fine-scale movement patterns of tagged Atlantic sturgeon, a HPE filter of $<50 \mathrm{~m}$ was used. Locations with $>50 \mathrm{~m}$ HPE were removed using a filter for trajectory analysis which was carried out using the adehabitatLT package (Calenge 2011) in R (R Development Core Team 2010). Because many individuals were present within the array on a number of occasions, trajectories were separated into a number of sections based on date and time of detection. Six-hour intervals were used to separate trajectories because the semi-diurnal tides in the area would likely displace the animal at low tide (i.e. would not be detected). Only trajectories with more than 5 relocations were used for assessment.

Trajectories were described using 4 measured variables: (1) the distance between successive relocations; (2) rate of movement (ROM; $\mathrm{m} \mathrm{s}^{-1}$ ); (3) turning angle, which measures the change in direction between relocations as defined by Calenge et al. (2009) and Calenge (2011); and (4) a linearity ratio. Linearity ratios were established for each trajectory by calculating the distance between steps and dividing by the total distance (sum of each of the steps) where values approaching 1 indicated linear movement, and values approaching 0 indicated tortuous movement (Heupel et al. 2012). Central tendencies (mean) and dispersion values (standard deviation) were also calculated for all variables, excluding linearity ratios. A correlation matrix plot was produced using the $\mathrm{R}$ package corrplot (Wei 2012) and strongly correlated variables ( $>30 \%$ correlation) were removed from further analysis. A within-group sum of squares plot was used to identify 3 clusters in the trajectory data set. A k-means cluster analysis was used to partition bursts into one of the 3 identified clusters. Cluster analysis was done using the R (R Development Core Team 2010) package cluster (Maechler et al. 2002). Clusters were henceforth referred to as movement
Type 1, movement Type 2, and movement Type 3. Univariate analyses of variance (ANOVA) were used to test for the significance of each of the metric variables in characterizing sturgeon trajectories. Tukey's honestly significant difference (HSD) post hoc test was used on significant tests to identify the source of any variation.

A univariate ANOVA was used to test for significant differences in type of movement performed by tagged sturgeon and time of day. Qualitative data was recorded for each movement type based on water level (i.e. high, mid, and low water levels) and tidal stage (i.e. flood and ebb) at the time the movement was performed. An ANOVA was used to test for significant differences between movement type and mean tide level. In addition, ANOVAs tested for significant differences in when each movement type began and ended in relation to water level. Chisquare contingency tests were employed to determine any significance in the proportions of movement type between water level and tidal stage.

\section{RESULTS}

\section{Trajectories and movement types}

Of the 83 sturgeon tagged, 33 were detected within the boundaries of the array between 14 June and 6 October 2011. After HPE and relocation filtration, data from 25 individuals were analyzed for fine-scale patterns. The number of analyzed trajectories per tagged sturgeon ranged from 1 to 20 (Table 1), with 94 sturgeon trajectories analyzed in total. The mean $( \pm \mathrm{SD})$ fork length of all monitored sturgeon was $128.8 \pm 17.5 \mathrm{~cm}$.

Mean distance travelled, mean turn angle, mean ROM, and linearity were the remaining non-confounding metric variables used for further analysis (Fig. 3). All movement metrics were found to differ significantly between movement types with the exception of mean turn angle (Fig. 4). Movement Type 1 was characterized by low mean distance traveled, low ROM, and a medium linearity value (Fig. 5). Movement Type 2 was characterized by medium mean travel distance, high ROM, and a high linearity value (Fig. 5). Lastly, movement Type 3 was characterized by a high mean distance of travel, high ROM, and a low linearity value (Fig. 5).

Tagged individuals displayed considerable variability in their types of movements. Overall, 11 of 25 individuals had 3 or more recorded trajectories. Of those 11 individuals, 1 displayed a single type of 
Table 1. Acipenser oxyrinchus. Summary of trajectory analysis for Atlantic sturgeon tracked in Vemco Positioning System (VPS) at Kingsport Beach, Minas Basin. The number of analyzed bursts for each sturgeon ID is given. The mean number of calculated relocations $( \pm \mathrm{SD})$ was determined for all bursts for a particular ID. These measurements do not take into account time spent outside of the array in between those detections. Dates are given as $\mathrm{dd} / \mathrm{mm} / \mathrm{yyyy}$

\begin{tabular}{|ccccccc|}
\hline Tag ID & $\begin{array}{c}\text { No. of } \\
\text { bursts }\end{array}$ & $\begin{array}{c}\text { Mean no. } \\
\text { calculated } \\
\text { relocations } \pm \text { SD }\end{array}$ & $\begin{array}{c}\text { Date and time } \\
\text { begin (first burst) }\end{array}$ & $\begin{array}{c}\text { Date and time } \\
\text { end (final burst) }\end{array}$ \\
\hline 16140 & 1 & 20.0 & $20 / 06 / 2011$ & $05: 05$ & $20 / 06 / 2011$ & $05: 31$ \\
16145 & 20 & $30.5 \pm 40.1$ & $05 / 08 / 2011$ & $19: 35$ & $07 / 09 / 2011$ & $18: 35$ \\
16147 & 4 & $11.0 \pm 5.0$ & $04 / 08 / 2011$ & $05: 45$ & $08 / 08 / 2011$ & $17: 12$ \\
47648 & 8 & $22.0 \pm 8.3$ & $11 / 08 / 2011$ & $08: 56$ & $22 / 08 / 2011$ & $20: 51$ \\
47671 & 1 & 31.0 & $28 / 06 / 2011$ & $20: 21$ & $28 / 06 / 2011$ & $21: 01$ \\
47674 & 1 & 6.0 & $18 / 06 / 2011$ & $03: 37$ & $18 / 06 / 2011$ & $06: 37$ \\
47680 & 3 & $27.0 \pm 23.6$ & $12 / 08 / 2011$ & $03: 37$ & $19 / 08 / 2011$ & $06: 42$ \\
15516 & 2 & $89.0 \pm 73.5$ & $04 / 07 / 2011$ & $16: 57$ & $06 / 07 / 2011$ & $09: 00$ \\
15518 & 7 & $15.3 \pm 11.5$ & $23 / 06 / 2011$ & $03: 40$ & $19 / 08 / 2011$ & $20: 17$ \\
15520 & 5 & $16.6 \pm 16.9$ & $16 / 08 / 2011$ & $16: 05$ & $26 / 08 / 2011$ & $10: 59$ \\
15521 & 3 & $33.7 \pm 32.9$ & $14 / 07 / 2011$ & $11: 53$ & $03 / 08 / 2011$ & $04: 30$ \\
15523 & 2 & $11.0 \pm 8.5$ & $04 / 08 / 2011$ & $14: 54$ & $04 / 08 / 2011$ & $20: 30$ \\
15534 & 1 & 9.0 & $14 / 08 / 2011$ & $04: 34$ & $14 / 08 / 2011$ & $05: 01$ \\
15539 & 1 & 12.0 & $30 / 07 / 2011$ & $00: 49$ & $30 / 07 / 2011$ & $03: 33$ \\
15541 & 3 & $16.3 \pm 3.2$ & $08 / 07 / 2011$ & $22: 36$ & $09 / 07 / 2011$ & $10: 49$ \\
15542 & 2 & $28.0 \pm 1.4$ & $08 / 07 / 2011$ & $17: 26$ & $07 / 08 / 2011$ & $21: 53$ \\
15543 & 2 & $33.0 \pm 8.5$ & $08 / 07 / 2011$ & $17: 44$ & $09 / 07 / 2011$ & $07: 14$ \\
15546 & 1 & 27.0 & $23 / 08 / 2011$ & $19: 33$ & $23 / 08 / 2011$ & $21: 28$ \\
15547 & 3 & $7.0 \pm 2.7$ & $08 / 07 / 2011$ & $17: 19$ & $21 / 08 / 2011$ & $16: 39$ \\
15548 & 2 & $32.5 \pm 21.9$ & $08 / 07 / 2011$ & $17: 31$ & $08 / 08 / 2011$ & $23: 01$ \\
15549 & 1 & 21.0 & $08 / 07 / 2011$ & $17: 56$ & $08 / 07 / 2011$ & $19: 00$ \\
15550 & 1 & 43.0 & $08 / 07 / 2011$ & $18: 09$ & $08 / 07 / 2011$ & $19: 58$ \\
15551 & 9 & $26.1 \pm 43.5$ & $08 / 07 / 2011$ & $18: 49$ & $27 / 08 / 2011$ & $07: 32$ \\
15560 & 9 & $33.8 \pm 20.7$ & $22 / 08 / 2011$ & $16: 05$ & $26 / 09 / 2011$ & $16: 02$ \\
15567 & 2 & $8.0 \pm 2.8$ & $03 / 08 / 2011$ & $01: 45$ & $04 / 08 / 2011$ & $14: 33$ \\
\hline
\end{tabular}

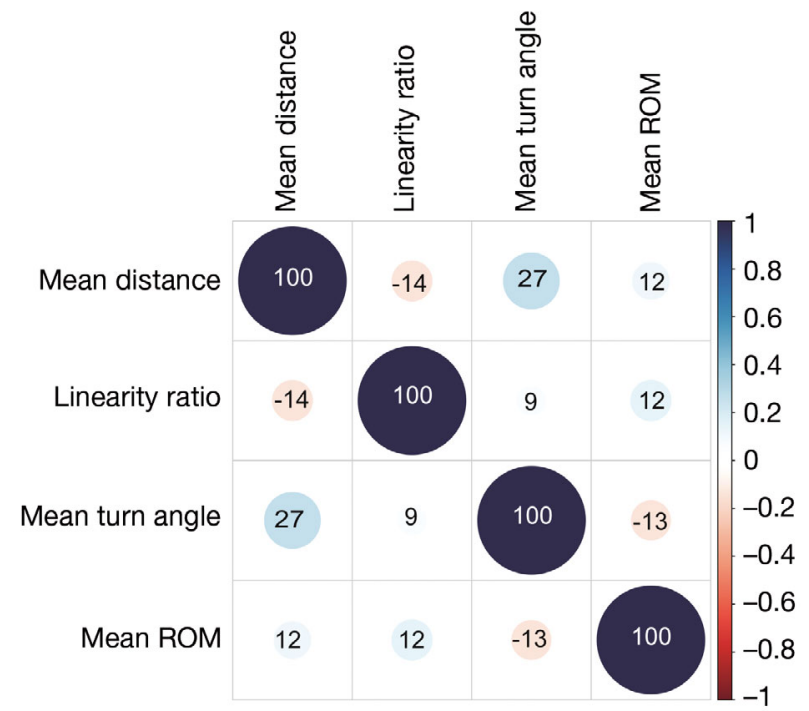

Fig. 3. Correlation matrix of movement metrics used in trajectory analysis. Mean distance $=$ mean distance travelled between calculated relocations, Linearity ratio = linearity (or straightness) of movement trajectory, Mean turn angle = mean turn angle of movement trajectory, and Mean ROM = mean rate of movement travelled. The relative circle sizes relate to the absolute value of corresponding correlation coefficients (larger size $=$ stronger correlation). Values within circles $=\%$ correlation movement, 2 displayed 2 types of movement, and 8 displayed all 3 movement types at some point during their monitoring period, indicating that most sturgeon change from one movement type to another. Overall, $40.4 \%$ of the trajectories were classified as movement Type 1, 40.4\% as movement Type 2, and $19.2 \%$ as movement Type 3.

\section{Diel and tidal activity}

All movement types occurred at varying times throughout a $24 \mathrm{~h}$ period ( $\mathrm{n}=94$, df $=1, \mathrm{p}=0.13)$, however, sturgeon were found to be most active during dawn and dusk (Fig. 6). Sturgeon were detected more often during a flood rather than an ebb tide. However, the type of movement (i.e. Types 1, 2, and 3) did not differ significantly between the flood and the ebb tides $\left(\chi^{2}=0.97\right.$, df $\left.=2, p=0.62\right)$, nor between water levels (i.e. high, low, $\mathrm{mid} / \mathrm{slack}_{;} \chi^{2}=6.07$, $\mathrm{df}=4, \mathrm{p}=0.19$ ).

\section{DISCUSSION}

Using calculated relocations from an intertidal VPS, we were able to successfully identify and quantify 3 different movement patterns exhibited by adult Atlantic sturgeon. Our results may provide the first step in a more detailed understanding of behavioural drivers underlying movement data. The main differences between identified behaviours were mean ROM, mean distance travelled between relocations, and linearity of the trajectory. These movement metrics revealed fine-scale behavioural shifts not previously described for adult Atlantic sturgeon. Directional and non-directional movements have been described for green sturgeon Acipenser medirostris (Ayres, 1854) based on swim speed and depth metrics (Kelly et al. 2007). Nondirectional behaviour consisted of slow and erratic movements on or near the substrate, whereas directional behaviour was faster, more linear and higher in the water column where the fish occasionally actively moved to cover long distances (Kelly et al. 2007). Although motivation behind exhibited behaviour is difficult to confirm, studying 

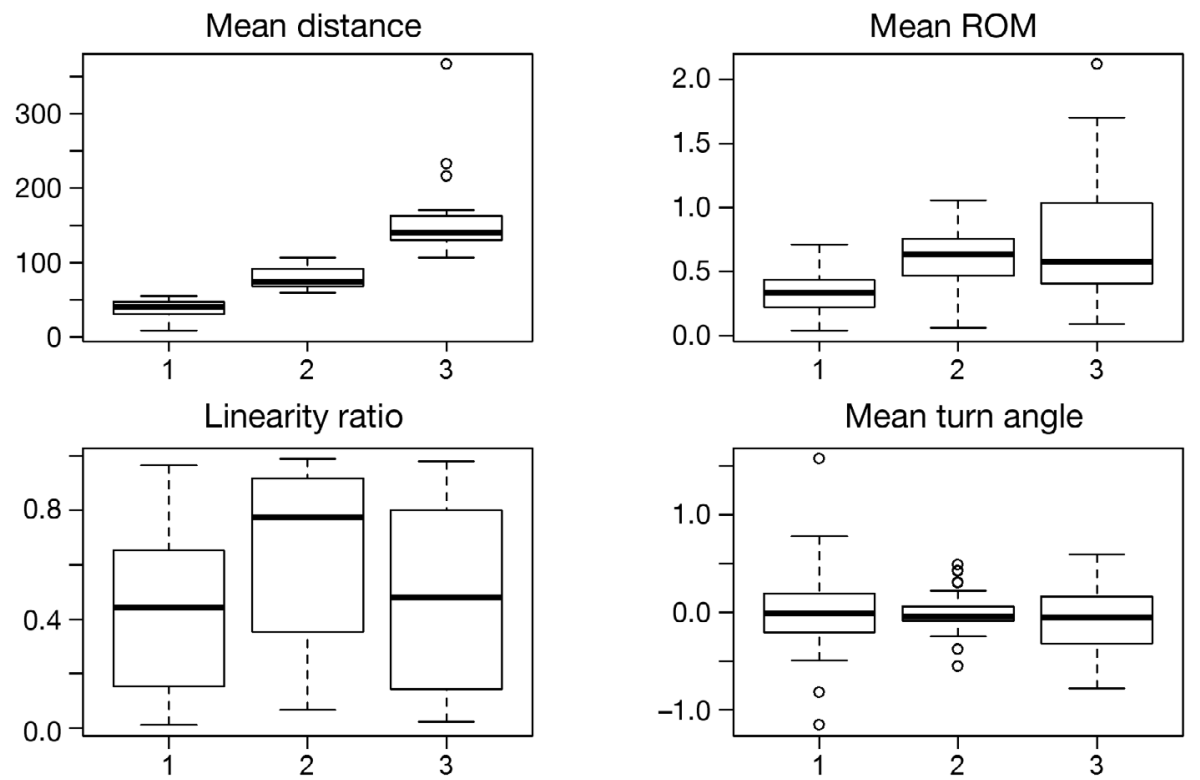

Fig. 4. Acipenser oxyrinchus. Four calculated metric variables used to distinguish movement types in Atlantic sturgeon burst trajectories. $x$-axis represents movement Types 1, 2, and 3, respectively (see 'Results: Trajectories and movement types' for definitions). Univariate analyses of variance were used to test for significance. All p < 0.05, except mean turn angle. Tukey's honestly significant difference post hoc test was used for all significant categories (i.e. mean distance, mean rate of movement [ROM], and linearity). There was significant variation between all 3 movement types in each category with the exception of the linearity values of movement Type 1 and movement Type 3 . The box extends from the 25th to the 75th percentile of observations (interquartile range), with the center line indicating the median. The whiskers represent the upper and lower adjacent values. The circles denote observed points outside the adjacent values in a period

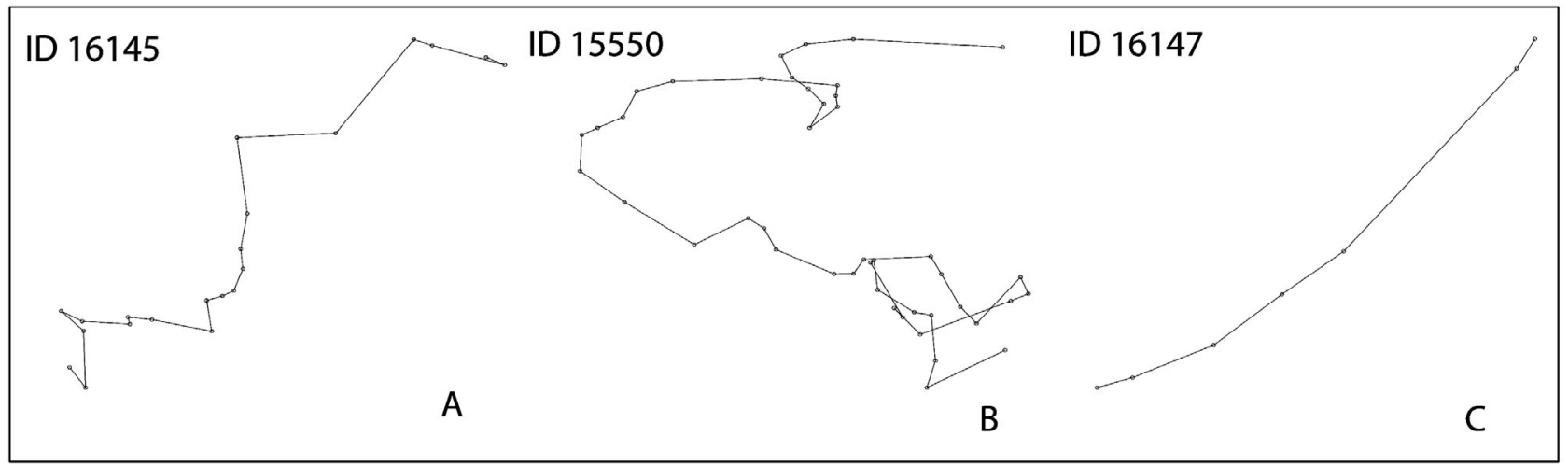

Fig. 5. Acipenser oxyrinchus. Examples of trajectory bursts in each of 3 movement types. (A) Movement Type 1 trajectories were characteristically slow and winding or ' $\mathrm{S}$ ' shaped, with short steps in between relocations. Total distance moved by sturgeon ID 16145 was $1044.29 \mathrm{~m}$, with a mean distance of $52.22 \mathrm{~m}$ between relocations. The linearity ratio for this trajectory was 0.61 , and mean rate of movement (ROM) was $0.29 \mathrm{~m} \mathrm{~s}^{-1}$. (B) Movement Type 2 trajectories were fast and tortuous. Total distance moved by sturgeon ID 15550 was $3019.19 \mathrm{~m}$, with a mean distance of $71.89 \mathrm{~m}$ between relocations. The linearity ratio for this trajectory was 0.19 , and mean ROM was $0.49 \mathrm{~m} \mathrm{~s}^{-1}$. (C) Movement Type 3 trajectories were fast and linear, with large steps in between relocations. Total distance moved by sturgeon ID 16147 was $856.09 \mathrm{~m}$, with a mean distance of $142.68 \mathrm{~m}$ between relocations. The linearity ratio for this trajectory was 0.98 , and mean ROM was $0.78 \mathrm{~m} \mathrm{~s}^{-1}$

fine-scale movements in relation to other factors such as environment and/or prey availability provides indications of an animal's incentive.

The non-directional behaviour displayed by green sturgeon Acipenser medirostris was presumably associated with foraging in areas of high prey abun- dance (Kelly et al. 2007). Foraging behaviour has been experimentally observed for a number of sturgeon species. To examine olfactory cues in relation to various behaviours, Kasumyan (1999) put adult green, Russian A. guelenstaedtii (Linnaeus, 1758), Siberian A. baerii (Brandt, 1869), stellate $A$. 


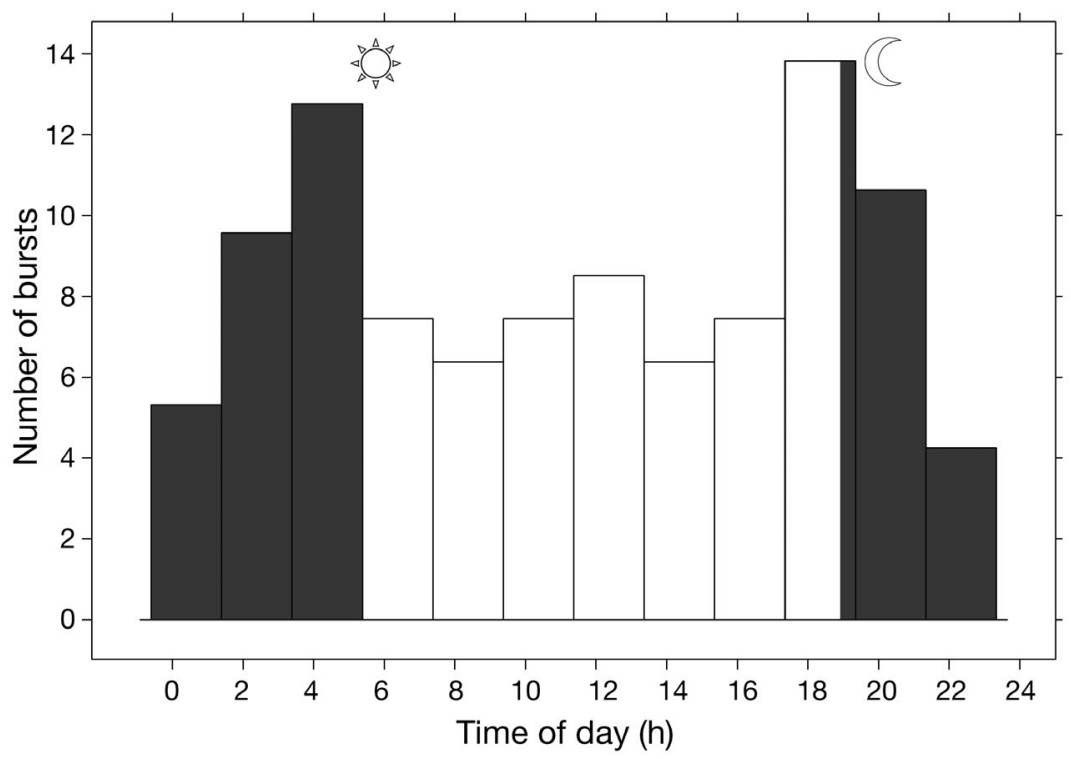

Fig. 6. Acipenser oxyrinchus. Frequency of occurrence for Atlantic sturgeon bursts during time of day showing increased crepuscular activity by tagged sturgeon

stellatus (Pallas, 1771) and beluga Huso huso (Linnaeus, 1758) sturgeon in holding tanks and observed swimming behaviour in response to prey odours which were placed randomly within the tank. Kasumyan (1999) recognized a crowding by sturgeon to areas containing maximum concentrations of food odour; once the area was located, sturgeon began to move in winding or ' $\mathrm{S}$ ' shaped trajectories trailing barbells on the substratum, and often attacking the bottom in an attempt to ingest food. In our study, movement Type 1 appears to be indicative of this same feeding behaviour as many of the trajectories in this category were winding with slow movements and short time steps. A change in movement, particularly lowering of swim speed and decrease in turn rate may be an approach to intensify the search within a prey patch. If sturgeon located a reliable prey source, then the short steps between relocations may indicate feeding within that patch.

A change from one movement type to another may be driven by various factors including increased competition for resources, changing prey availability, or the risk of predation (Heupel et al. 2012). In addition to these factors, mobile species in the Minas Basin have to accommodate the extreme semidiurnal tidal fluctuations which limit intertidal foraging time and increase the demand for optimal foraging practice. In our study, movement Type 2 trajectories were erratic and tortuous and resembled a searching pattern. Because of the tortuous nature of these movements, a large area of the intertidal zone was often covered during a single analyzed trajectory. Increased sinuosity is common in foraging animals, and most foraging animals decrease swimming speed when patches of high food abundance are encountered (Coughlin et al. 1992). In our case, movement Type 2 may be representative of a searching behaviour, whereas movement Type 1 is a behaviour adopted once a suitable prey patch is identified. Since most individuals performed all 3 movement types at some point during the study, it is not unreasonable to suggest that the motivation to change from one movement type to another may be driven by foraging activity in the intertidal zone.

Atlantic sturgeon also made rapid, straight-line travel movements (i.e. movement Type 3). These were, however, not as frequent as the other 2 types of movement and generally occurred outside of the intertidal zone. Movement Type 3 occurred in the deeper water off the intertidal zone at the Cornwallis River estuary mouth, where large influxes of fresh water enter the Minas Basin from 3 rivers - the Cornwallis, Canard, and Habitant. Due to strong currents, high turbidity, low average salinity and variable temperatures found within the estuary, markedly fewer organisms reside there in contrast to the surrounding salt marshes and tidal flats (Daborn et al. 2004). Rapid straight-line travel can represent an extensive search mode in areas of poorer food quality as animals try to minimize the time spent between patches and reduce the chance of repeat visits to the same patch (Zollner \& Lima 1999). Thus, rapid, straight-line travel may represent transitory movement through this area, indicative of movement between patches of food. Unlike movement Types 1 and 2, movement Type 3 did not occur in the intertidal feeding zone, which further supports our contention that movement Types 1 and 2 are behaviours primarily associated with foraging or searching.

McLean et al. (2013) collected and analyzed Atlantic sturgeon stomach samples concurrently with our deployment of acoustic tags. Their results indicated a high proportion of prey items consumed are benthic polychaete worms, primarily Clymanella spp. and Spiophanes bombyx - both present on the Minas Basin mudflats. Atlantic sturgeon diet analyses in other oceanic and estuarine systems have also 
reported a dietary preference for benthic invertebrates (Johnson et al. 1997, Haley 1999, Savoy 2007, Guilbard et al. 2007). The polychaete species comprising over $99 \%$ of the Atlantic sturgeon diet in Minas Basin are more abundant in low and midintertidal regions (G. Gibson unpubl. data) and inhabit substrates with larger grain sizes (Hicklin \& Smith 1984). Bottom-type within the VPS study area was primarily sandy/silt with patches of mud, silt and sand. Benthic invertebrate distributions most likely reflect the patchiness in sediment type and thus explain some of the behaviours of tagged Atlantic sturgeon as they search for suitable bottom type and prey patches.

Although time of day was not a significant predictor of movement type, an increase in overall activity at dawn and dusk is an important temporal activity pattern not previously documented for adult Atlantic sturgeon. We hypothesize that the increased crepuscular activity displayed by Atlantic sturgeon is partially related to prey availability. Nocturnal behaviour has been described for other sturgeon species, including the white sturgeon, which increased swimming speeds at night and occupied shallower waters than during the day (Parsley et al. 2008). The increased rate of movement does not necessarily imply increased foraging behaviour, but may suggest that sturgeon were making diel migrations to exploit prey that is more prevalent in shallower water at night, or to follow mobile prey (Parsley et al. 2008). White sturgeon diet consists of invertebrates as well as some species of fish (McCabe et al. 1993), so following migratory mobile prey that are more active at night may explain the observed nocturnal activity patterns. Atlantic sturgeon diet rarely consists of other fish species; however, the occasional sand lance Ammodytes spp. has been noted (Dadswell 2006). Sand lances are present in the Minas Basin, but there is no record of the summer aggregation of Atlantic sturgeon in Minas Basin feeding on them, so the tracking of mobile prey is not a likely explanation for our observed diel patterns. Most of the Minas Basin aggregation of Atlantic sturgeon feed solely on tubedwelling polychaetes (McLean et al. 2013) which are primarily negatively phototactic but often rely on light cues at dawn and dusk to synchronize reproductive activities (Rupert et al. 2004). Oligochaetes have also been identified as being positively phototactic to dim light levels such as would occur during dawn and dusk.

Fishes in Minas Basin have been reported to move onto the intertidal zone during high tide and off during low tide (Rulifson et al. 2008). During our study,
Atlantic sturgeon entered the study area on a flood tide more often than on an ebb tide, suggesting that they were moving with the flooding tide, likely to increase the amount of foraging time on the mudflats. While tidal stage and water-level were not significant factors in observed movement types, tidal stage is likely still critical to the movements of individuals overall (i.e. foraging habitat accessibility). This pattern has also been observed in a number of shark species. The leopard shark Tirakis semifasciata (Girard, 1855) significantly moved towards the inner bay with the incoming tide-presumably to exploit food resources (Ackerman et al. 2000). Similarly, in another California estuary, female leopard shark distribution and movements were strongly influenced by the tides; and in some regions of the estuary, the sharks would move with the tide in order to maximize the area over which they could forage (Carlisle \& Starr 2010). Like foraging sturgeon, leopard sharks display a high degree of plasticity in diet and are often recorded foraging on different prey items depending on what is locally available (Carlisle \& Starr 2010). By moving with the tide, individuals are able to gain access to the different prey items that are abundant in various areas of the estuary, therefore increasing their likelihood of discovering a suitable prey patch.

The quantification of movement paths can improve our understanding of the foraging strategies of marine predators in a system where direct observations of feeding behaviour are rare (Bailey \& Thompson 2006). Further, identifying fine-scale movement patterns can provide insight into understanding the motivations or drivers behind the movements made. For Atlantic sturgeon, much of this motivation is likely foraging strategy, as they exploit the tidal flats at high tide and spend more than $80 \%$ of their time displaying foraging or searching behaviours. Since successful food acquisition is crucial to an animal's growth, reproductive viability, survival and fitness, identifying important foraging areas through observing foraging behaviour allows for the characterization of critical habitat, which plays a central role in developing proper management strategies for protecting species of concern. Atlantic sturgeon are occasionally captured as by-catch in commercial flounder trawls. Although the overall stress impact on sturgeon captured as by-catch in the Minas Basin ground-fish fishery has been shown to be minimal (Beardsall et al. 2013), any interruption to periods of foraging may result in the sturgeon's inability to obtain their daily ration, and may have an overall negative impact on fitness. 
Acknowledgements. We thank J. Broome, J. Beardsall, and a number of other invaluable field assistants. We also thank F. Smith and R. Vallee from Vemco for assisting in VPS design and data processing. We thank P. Illsley of NSCC for providing the necessary bathymetric map data of Kingsport Beach. This project was funded by the Canada Foundation for Innovation grant to the Global Ocean Tracking Network centred at Dalhousie University, and by the National Science and Engineering Research Council, Strategic Network Grant to the Ocean Tracking Network Canada, primary investigator Dr. S. Iverson, Dalhousie University. M.J.W.S. was supported by the Canada Research Chairs program. Fishing was performed under the Department of Fisheries and Oceans Scientific Licence to Fish \#322595. Tagging procedures were performed under Acadia Animal Care Committee protocol \#07-11.

\section{LITERATURE CITED}

Ackerman JT, Kondratieff MC, Matern SA, Cech JJ Jr (2000) Tidal influence on spatial dynamics of leopard sharks, Triakis semifasciata, in Tomales Bay, California. Environ Biol Fishes 58:33-43

ASMFC (Atlantic States Marine Fisheries Commission) (1998) Fishery management plan for Atlantic sturgeon. Fisheries Management Report 17, Washington, DC

> Austin D, Bowen WD, McMillan JI (2004) Intraspecific variation in movement patterns: modeling individual behaviour in a large marine predator. Oikos 105:15-30

Bailey H, Thompson P (2006) Quantitative analysis of bottlenose dolphin movement patterns and their relationship with foraging. J Anim Ecol 75:456-465

Bailey H, Shillinger G, Palacios D, Bograd S, Spotila J, Paladino F, Block B (2008) Identifying and comparing phases of movement by leatherback turtles using state-space models. J Exp Mar Biol Ecol 356:128-135

- Beardsall JW, McLean MF, Cooke SJ, Dadswell MJ, Wilson BC, Redden AM, Stokesbury MJW (2013) Consequences of incidental otter trawl capture on survival and physiological condition of threatened Atlantic sturgeon Acipenser oxyrinchus. Trans Am Fish Soc 142:1202-1214

Benhamou S (2004) How to reliably estimate the tortuosity of an animal's path: straightness, sinuosity, or fractal dimensions? J Theor Biol 229:209-220

Bousfield EL, Leim AH (1958) The fauna of Minas Basin and Minas Channel. National Museum of Canada Bulletin No. 166, Department of Northern Affairs and Natural Resources, Ottawa

Calenge C (2011) Analysis of animal movements in R: the adehabitatLT package. R Foundation for Statistical Computing, Vienna

Calenge C, Dray S, Royer-Carenzi M (2009) The concept of animals' trajectories from a data analysis perspective. Ecol Inform 4:34-41

Carlisle AB, Starr RM (2010) Tidal movements of female leopard sharks (Triakis semifasciata) in Elkhorn Slough, California. Environ Biol Fishes 89:31-45

Collins MR, Smith TIJ, Post WC, Pashuk O (2000) Habitat utilization and biological characteristics of adult Atlantic sturgeon in two South Carolina Rivers. Trans Am Fish Soc 129:982-988

Collins AB, Heupel MR, Motta PJ (2007) Residence and movement patterns of cownose rays Rhinoptera bonasus within a south-west Florida estuary. J Fish Biol 71: 1159-1178
COSEWIC (Committee on the Status of Endangered Wildlife in Canada) (2011) COSEWIC assessment and status report on the Atlantic sturgeon Acipenser oxyrinchus in Canada. Committee on the Status of Endangered Wildlife in Canada, Ottawa

Coughlin DJ, Strickler JR, Sanderson B (1992) Swimming and search behaviour in clownfish, Amphiprion perideraion, larvae. Anim Behav 44:427-440

Daborn GR, van Proosdij D, Spooner IS (2004) Intertidal systems of the Minas Basin, Bay of Fundy. Field guide prepared for the AGU Chapman conference on salt marsh geomorphology, Halifax

> Dadswell MJ (2006) A review of the status of Atlantic sturgeon in Canada, with comparisons to populations in the United States and Europe. Fisheries 31:218-229

DFO (Fisheries and Oceans Canada) (2012) Proceedings of the regional peer review meeting on the recovery potential assessment for Atlantic sturgeon (Acipenser oxyrinchus) St. Lawrence population. Canadian Science Advisory Secretariat Proceedings Series 2012/039, Québec City

> Erickson DL, Kahnle A, Millar MJ, Mora EA and others (2011) Use of pop-up satellite archival tags to identify oceanic- migratory patterns for adult Atlantic sturgeon, Acipenser oxyrinchus oxyrinchus Mitchill, 1815. J Appl Ichthyol 27:356-365

Espinoza M, Farrugia TJ, Webber DM, Smith F, Lowe CG (2011a) Testing a new acoustic telemetry technique to quantify long-term, fine-scale movements of aquatic animals. Fish Res 108:364-371

Espinoza M, Farrugia TJ, Lowe CG (2011b) Habitat use, movements and site fidelity of the gray-tooth hound shark (Mustelus californicus Gill 1863) in a newly restored southern California estuary. J Exp Mar Biol Ecol 401:63-74

Farrugia TJ, Espinoza M, Lowe CG (2011) Abundance, habitat use and movement patterns of the shovelnose guitarfish (Rhinobatos productus) in a restored southern California estuary. Mar Freshw Res 62:648-657

> Fernandes SJ, Zydlewski GB, Zydlewski JD, Wippelhauser GS, Kinnison MT (2010) Seasonal distribution and movements of shortnose sturgeon and Atlantic sturgeon in the Penobscot River Estuary, Maine. Trans Am Fish Soc 139: 1436-1449

Fox DA, Breece MW (2010) Atlantic sturgeon (Acipenser oxyrinchus oxyrinchus) in the New York Bight DPS: identification of critical habitat and rates of interbasin exchange. NOAA award final report, Dover, DE

Fox DA, Hightower JE, Parauka FM (2000) Gulf sturgeon spawning migration and habitat in Choctawhatchee River system, Alabama-Florida. Trans Am Fish Soc 129: 811-826

Guilbard F, Munro J, Dumont P, Hatin D, Fortin R (2007) Feeding ecology of Atlantic sturgeon and lake sturgeon co-occurring in the St. Lawrence estuarine transition zone. Am Fish Soc Symp 56:85-104

Haley NJ (1999) Habitat characteristics and resource use patterns of sympatric sturgeons in the Hudson River estuary. MSc dissertation, University of Massachusetts, Amherst, MA

Hatin D, Munro J, Caron F, Simons RD (2007) Movements, home range size, and habitat use and selection of early juvenile Atlantic sturgeon in the St Lawrence estuarine transition zone. Am Fish Soc Symp 56:129-155

> Heupel MR, Simpfendorfer CA, Heuter RA (2004) Estima- 
tion of shark home ranges using passive monitoring techniques. Environ Biol Fishes 71:135-142

- Heupel MR, Simpfendorfer CA, Olsen EM, Moland E (2012) Consistent movement traits indicative of innate behavior in neonate sharks. J Exp Mar Biol Ecol 432-433:131-137

Hicklin PW, Smith PC (1984) Selection of foraging sites and invertebrate prey by migrant semipalmated sandpipers, Calidris pusilla (Pallas), in Minas Basin, Bay of Fundy. Can J Zool 62:2201-2210

> Hissmann K, Fricke H, Schauer J (2000) Patterns of time and space utilisation in coelacanths (Latimeria chalumnae), determined by ultrasonic telemetry. Mar Biol 136: 943-952

Holland KN, Wetherbee BM, Peterson JD, Lowe CG (1993) Movements and distribution of hammerhead shark pups on their natal grounds. Copeia 1993:495-502

> Johnson JH, Dropkin DS, Warkentine BE, Rachlin JW, Andrews WD (1997) Food habits of Atlantic sturgeon off the central New Jersey coast. Trans Am Fish Soc 126: $166-170$

Jonsen ID, Myers RA, James MC (2007) Identifying leatherback turtle foraging behaviour from satellite-telemetry using a switching state-space model. Mar Ecol Prog Ser 337:255-264

Kasumyan AO (1999) Olfaction and taste senses in sturgeon behaviour. J Appl Ichthyol 15:228-232

Kelly JT, Klimley AP, Crocker CE (2007) Movements of green sturgeon, Acipenser medirostris, in the San Francisco Bay estuary, California. Environ Biol Fishes 79: 281-295

Kieffer MC, Kynard B (1993) Annual movements of shortnose and Atlantic sturgeons in the Merrimack River, Massachusetts. Trans Am Fish Soc 122:1088-1103

Lindley ST, Moser ML, Erickson DL, Belchik M and others (2008) Marine migration of North American green sturgeon. Trans Am Fish Soc 137:182-194

Maechler M, Rousseeuw P, Struyf A, Hubert M (2002) Package 'cluster': cluster analysis extended. R Foundation for Statistical Computing, Vienna

McCabe GT Jr, Emmett RL, Hinton SA (1993) Feeding ecology of juvenile white sturgeon (Acipenser transmontanus) in the lower Columbia River. Northwest Sci 67:170-180

McLean MF (2013) Feeding ecology and movement patterns of Atlantic sturgeon in Minas Basin, Bay of Fundy. MSc thesis, Acadia University, Wolfville

McLean MF, Dadswell MJ, Stokesbury MJW (2013) Feeding ecology of Atlantic sturgeon, Acipenser oxyrinchus oxyrinchus Mitchill, 1815 on the infauna of intertidal mudflats of Minas Basin, Bay of Fundy. J Appl Ichthyol 29: 503-509

Moser ML, Lindley ST (2007) Use of the Washington estuaries by subadult and adult green sturgeon. Environ Biol Fishes 79:243-253

Moser ML, Ross ST (1995) Habitat use and movements of shortnose and Atlantic sturgeons in the lower Cape Fear River, North Carolina. Trans Am Fish Soc 124:225-234

NOAA (National Oceanic and Atmospheric Administration) (2012a) Endangered and threatened wildlife and plants; threatened and endangered status for distinct population segments of Atlantic sturgeon in the northeast region. Fed Regist 77:5880-5912

NOAA (2012b) Endangered and threatened wildlife and plants; final listing for two distinct population segments of Atlantic sturgeon (Acipenser oxyrinchus oxyrinchus) in the southeast. Fed Regist 77:5914-5982

Parsley MJ, Popoff ND, Wright CD, van der Leeuw BK (2008) Seasonal and diel movements of white sturgeon in the lower Columbia River. Trans Am Fish Soc 137: 1007-1017

Percy JA (2001) Fundy's Minas Basin: multiplying the pluses of Minas. Bay of Fundy Ecosystem Partnership, Fundy Issues 19:1-12

R Development Core Team (2010) R: a language and environment for statistical computing. $\mathrm{R}$ Foundation for Statistical Computing, Vienna. Available at www.Rproject.org

Reubens J, Degraer S, Vincx M (2011) Aggregation and feeding behaviour of pouting (Trisopterus luscus) at wind turbines in the Belgian part of the North Sea. Fish Res 108:223-227

Rulifson RA, McKenna SA, Dadswell MJ (2008) Intertidal habitat use, population characteristics, movement, and exploitation of striped bass in the inner Bay of Fundy, Canada. Trans Am Fish Soc 137:23-32

Rupert EE, Fox RS, Barnes RD (2004) Invertebrate zoology: a functional evolutionary approach. Brooks/Cole, Belmont, CA

Savoy T (2007) Prey eaten by Atlantic sturgeon in Connecticut waters. Am Fish Soc Symp 56:157-165

Simpfendorfer CA, Heupel MR, Collins AB (2008) Variation in the performance of acoustic receivers and its implication for positioning algorithms in a riverine setting. Can J Fish Aquat Sci 65:482-492

Simpfendorfer CA, Wiley TR, Yeiser BG (2010) Improving conservation planning for an endangered sawfish using data from acoustic telemetry. Biol Conserv 143: 1460-1469

Smith F (2013) Understanding HPE in the Vemco Positioning System (VPS). http://vemco.com/wp-content/uploads/ 2013/09/understanding-hpe-vps.pdf (accessed 29 November 2013)

Vladykov VD, Greeley JR (1963) Order Acipenseroidei. Contributions du Departement des Pêcheries Quebec 53: $26-27$

Wei T (2012) Package 'corrplot': correlation plot. R Foundation for Statistical Computing, Vienna

> Welch DW, Melnychuk MC, Rechisky ER, Porter AD and others (2009) Freshwater and marine migration and survival of endangered Cultus Lake sockeye salmon (Oncorhynchus nerka) smolts using POST, a large-scale acoustic telemetry array. Can J Fish Aquat Sci 66:736-750

> Wirgin I, Maceda L, Waldman JR, Wehrell S, Dadswell M, King T (2012) Stock origin of migratory Atlantic sturgeon in the Minas Basin, inner Bay of Fundy, Canada determined by microsatellite and mitochondrial DNA analysis. Trans Am Fish Soc 141:1389-1398

> Yeiser BG, Heupel MR, Simpfendorfer CA (2008) Occurrence, home range and movement patterns of juvenile bull (Carcharhinus leucas) and lemon (Negaprion brevirostris) sharks within a Florida estuary. Mar Freshw Res 59:489-501

Yeo RK, Risk MJ (1979) Fundy tidal power: environmental sedimentology. Geosci Can 6:115-121

Zollner PA, Lima SL (1999) Search strategies for landscapelevel interpatch movements. Ecology 80:1019-1030 